\title{
A new trackway possibly made by a trotting theropod at the Las Hoyas fossil site (Early Cretaceous, Cuenca Province, Spain): Identification, bio-dynamics, and palaeoenvironmental implications
}

\author{
J.J. Moratalla, J. Marugán-Lobón, H. Martín-Abad, E. Cuesta, and A.D. Buscalioni
}

\begin{abstract}
Dinosaur footprints have recently been identified at the Las Hoyas fossil site, renewing interest in its trace fossils as aids in the interpretation of the area's palaeoenvironment and palaeocommunity. The varied tetrapod print morphologies found seem to have been influenced by the contemporaneous presence of microbial mats. This paper updates the information on tetrapod traces at the site and describes a new dinosaur trackway containing four tridactyl footprints. Although the trackway is not particularly well-preserved, the morphology of the toe marks, the heel surface, and the general morphology of the prints strongly suggest they were produced by a theropod dinosaur of medium size. Further, the ratio between the stride length and the deduced hip height suggest the trackmaker was trotting. Interestingly, the footprints are very similar in size to the pes of Concavenator, a carcharodontosaurid dinosaur known from skeletal material at the same locality. This new ichnological evidence reveals tetrapod prints to be more abundant toward the top of the site's stratigraphic succession. This suggests that, over time, the ecosystem evolved toward more frequent dry periods the dinosaurs present became able to walk in areas with shallow water and big dinosaurs walked across the ponding zone of Las Hoyas.
\end{abstract}

J.J. Moratalla. Instituto Geológico y Minero de España (Igme), Museo Geominero, Ríos Rosas 23, 28003 Madrid, Spain. j.moratalla@igme.es

J. Marugán-Lobón. Unidad de Paleontología, Universidad Autónoma de Madrid, Cantoblanco, 28049 Madrid, Spain and Dinosaur Institute, Natural History Museum of Los Angeles County, Los Angeles, CA, USA. jesus.marugan@uam.es

H. Martín-Abad. Jurassica Museum, Route de Fontenais 21, 2900 Porrentruy, Switzerland.

hugo.martin.abad@gmail.com and Department of Geosciences, University of Fribourg, Chemin du Musée 6, 1700 Fribourg, Switzerland

E. Cuesta. Unidad de Paleontología, Universidad Autónoma de Madrid, Cantoblanco, 28049 Madrid, Spain. elena.cuesta@uam.es

Moratalla, J.J., Marugán-Lobón, J., Martín-Abad, H., Cuesta, E. and Buscalioni, A.D. 2017. A new trackway possibly made by a trotting theropod at the Las Hoyas fossil site (Early Cretaceous, Cuenca Province, Spain): Identification, bio-dynamics, and palaeoenvironmental implications. Palaeontologia Electronica 20.3.59A: 1-14. https://doi.org/10.26879/770 palaeo-electronica.org/content/2017/2073-theropod-trackway-at-las-hoyas

Copyright: November 2017 Palaeontological Association.

This is an open access article distributed under the terms of Attribution-NonCommercial-ShareAlike 4.0 International (CC BY-NC-SA 4.0), which permits users to copy and redistribute the material in any medium or format, provided it is not used for commercial purposes and the original author and source are credited, with indications if any changes are made.

creativecommons.org/licenses/by-nc-sa/4.0/ 
A.D. Buscalioni. Unidad de Paleontología, Universidad Autónoma de Madrid, Cantoblanco, 28049 Madrid, Spain. angela.delgado@uam.es.

KEYWORDS: Barremian; Carcharodontosaurid; footprints; trotting dinosaur; microbial mats; taphonomy

Submission: 24 March 2017 Acceptance: 13 November 2017

\section{INTRODUCTION}

Although the deposits at the Las Hoyas site (Province of Cuenca, Spain) are known mainly for their abundant and well-preserved body fossils (Buscalioni and Poyato-Ariza, 2016), the site's trace fossils have proved essential in arriving at an understanding of the area's palaeoecological and palaeoenvironmental setting (Fregenal-Martínez and Meléndez, 2016). By complementing the body fossil record, trace fossils allow a much more complete picture of the fauna that inhabited the Las Hoyas palaeoecosystem to be discerned.

Invertebrate trace fossils at Las Hoyas were first documented by Fregenal-Martínez and Moratalla (1995) and Fregenal-Martínez et al. (1995). The ichnoassemblage was later updated by Buatois et al. (2000), who reported the presence of the ichnogenera Cruziana, Helminthoidichnites, Lockeia, Palaeophycus, and Treptichnus, and more recently by Gibert et al. (2016), who included the ichnogenus Planolites. The fish ichnotaxon Undichna unisulca is also frequent in the locality (Gibert et al., 1999). This ichnofacies is named Mermia and contains signs of characteristic benthic invertebrate activity - mainly that of crustaceans, worms, and insect larvae within continental environments (Buatois and Mángano, 2011). This Mermia interpretation is congruent with the body fossils present, which mainly represent obligate aquatic organisms such as benthic invertebrates and fish (Gibert et al., 1999; Buatois et al., 2000; Buscalioni and Fregenal-Martínez, 2010; Gibert et al., 2016). The Las Hoyas Mermia ichnoassemblage is rather peculiar, however, given the presence of archosaur trackways (Gibert et al., 2016).

The archosaur ichnofossils at Las Hoyas are less abundant than those of invertebrates, but have yielded significant information on the palaeoecology and palaeoenvironmental conditions of the ecosystem (Buscalioni and Fregenal-Martínez, 2010; Fregenal-Martínez and Meléndez, 2016). The tetrapod ichnofossils include some shallow footprints forming a crocodile trackway (Moratalla et al., 1995), a discovery that obliged the established palaeoenvironmental interpretation of a deep lake to be revisited and replaced with that of a rather shallow aquatic environment (Moratalla et al., 1995; Fregenal-Martínez and Meléndez, 2016). Buscalioni and Fregenal-Martínez (2010) reported Las Hoyas to have few tetrapod traces, although crocodilian body fossils are abundant. Dinosaurs are represented only by three specimens and species: Pelecanimimus polyodon (Pérez-Moreno et al., 1994), Concavenator corcovatus (Ortega et al., 2010), and cf. Mantellisaurus (Llandres et al., 2013). In fact, dinosaurs appear to have been only incidental organisms in the Las Hoyas ponding area (Buscalioni et al., 2008; Buscalioni and Fregenal-Martínez, 2010).

Early field work also yielded an isolated tridactyl footprint. This isolated footprint was first attributed to Pteraichnus (Lockley et al., 1995), then tentatively identified as turtle (Moratalla et al., 1995), and thereafter was reinterpreted as a theropod dinosaur (Vullo et al., 2009). New tetrapod ichnofossils were found in subsequent campaigns, including a theropod trackway composed of seven footprints (figure 5 in Gibert et al., 2016). This paper updates the information regarding the abundance of tracks in the stratigraphic succession of the Las Hoyas site. A second dinosaur trackway (LH-Y-1-001) is described, its state of preservation assessed, and its palaeoenvironmental implications discussed.

\section{GEOLOGICAL SETTING}

The Las Hoyas fossil site consists of finely laminated limestones within the La Huérguina Formation, a unit that records late Hauterivian-Barremian continental sedimentation in the southwestern Iberian Basin (Serranía de Cuenca, Spain) (Figure 1). On the basis of charophytes, ostracods, and palynomorphs the site has been dated as Late Barremian (Diéguez et al., 1995; Martín-Closas and Diéguez, 1998). The deposit represents a lacustrine to palustrine wetland in a freshwater carbonatic lentic ecosystem with a seasonal subtropical climate. There is no evidence of any marine influence (Poyato-Ariza et al., 1998; Bailleul et al., 2011). The wetland was drained by 


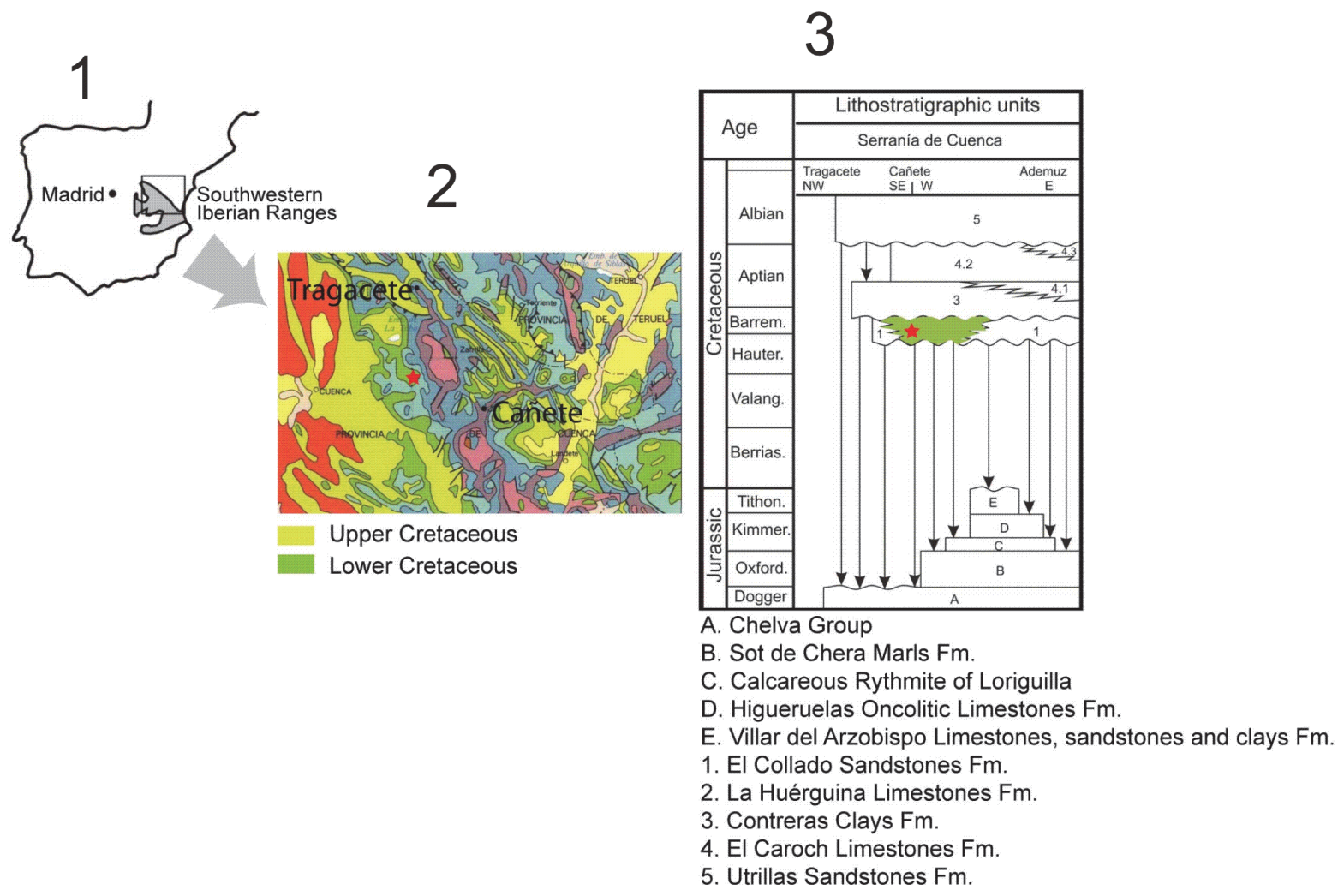

FIGURE 1. 1. Location of the Southwestern Iberian Ranges on the Iberian Peninsula. 2. Lithostratigraphic units of the Cretaceous of Iberian Basin. 3. Informal stratigraphy of La Huérguina Limestones Fm. in Las Hoyas and surrounding sub-basins (modified from Fregenal-Martínez and Meléndez, 2000).

carbonatic-rich water fed by groundwater and/or karstic aquifers (Fregenal-Martínez et al., 2014). The watered areas were shallow and covered by microbial mats (Briggs et al., 1997; Gupta el al., 2008). These ponding surfaces experienced seasonal oscillations in their water level (FregenalMartínez and Meléndez, 2000).

The laminated limestones of Las Hoyas reflect two petrographically differentiated facies associations (Fregenal-Martínez, 1998). One is the result of the sedimentation by traction and decantation of allochthonous elements (e.g., detrital carbonate particles, plant debris) and bio-induced calcium carbonate, deposited during seasonal flooding and longer-term wetter periods. The other is an autochthonously-produced facies composed of carbonate generated by the growth of thick mats of microbial communities during drier periods (Fregenal-Martínez, 1998). During drier periods, the depth of the water column was reduced to probably just a few centimeters. The drier facies are richer in fossils than the wetter facies and, in addition, dinosaur and crocodile footprints are commonly found on the drier facies (Fregenal-Martínez and Buscalioni, 2009; Buscalioni and Fregenal-Martínez, 2010).

\section{DISTRIBUTION AND TAPHONOMIC ASSESMENT OF TETRAPOD TRACES}

The Las Hoyas site has been the subject of layer-by-layer excavation since 1991 (Buscalioni and Fregenal-Martínez, 2010; Buscalioni and Poyato-Ariza, 2016). Small square areas of about 30 $\mathrm{m}^{2}$ are suitable for testing the homogeneity of the fossil associations throughout the layers. Each excavated area was named according to a color (Figure 2). The set of excavated squares follows a stratigraphic succession from Yellow (East) to Light Grey (West). Correlation of the squares was done by combining the analysis of microfacies and the fossil content at each layer (Buscalioni and Fregenal-Martínez, 2010), and by connecting some sampled areas in the locality (see Figure 2, corridors "Milky Line" and "Ma-Wh path"). Along the stratigraphic succession, some prints were found isolated on small areas, whereas on the extended 


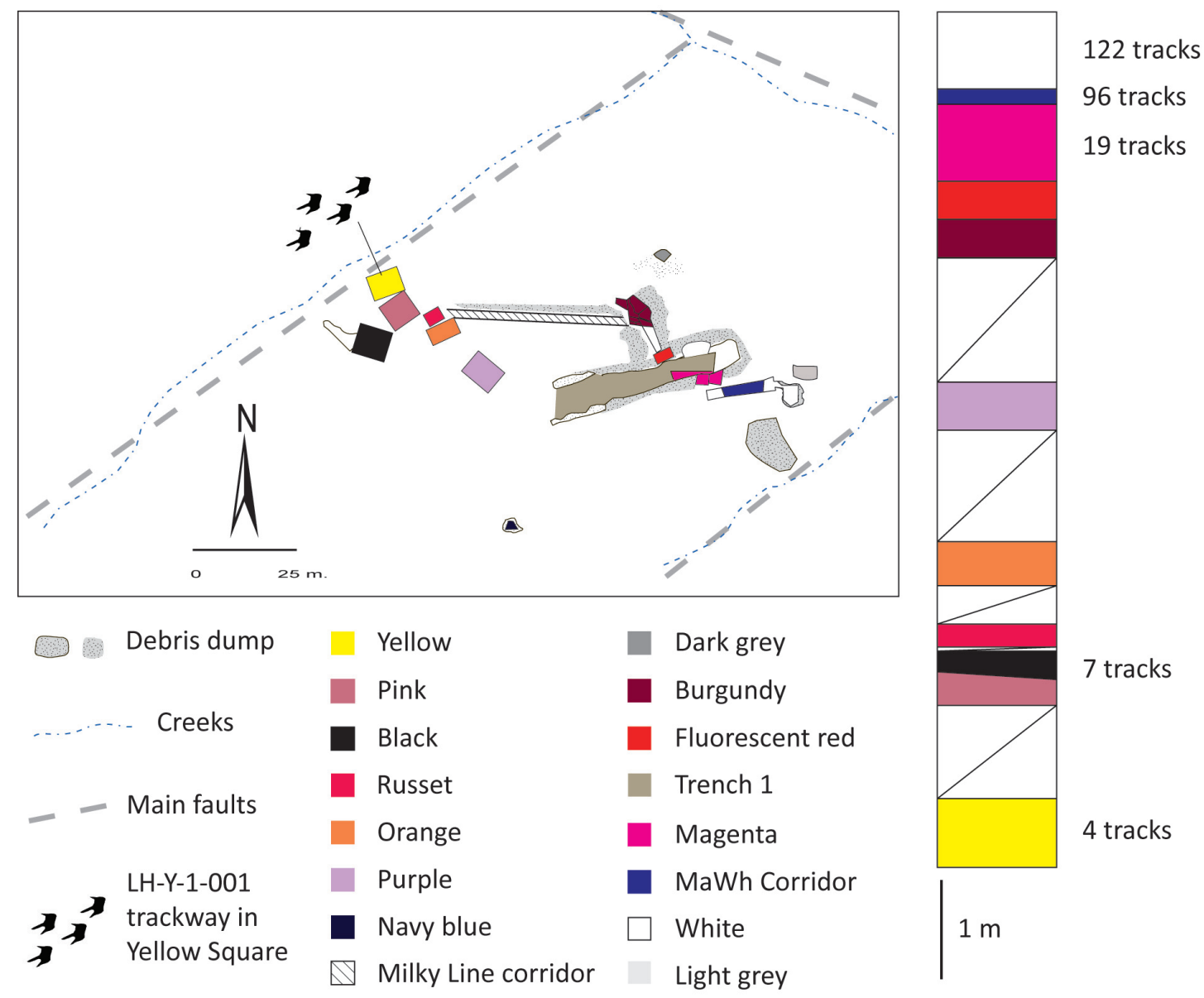

FIGURE 2. Map of the Las Hoyas quarry (upper Barremian, Cuenca, Spain) with the position of the E-W excavated Squares, in color (modified from Buscalioni and Fregenal-Martínez, 2010). As shown in the box, the stratigraphic succession of the squares, and the associated richness in the number of tetrapod tracks.

excavated squares, a set of traces or even trackways were discovered. The number of tetrapod traces increased from the bottom (Yellow) to the top (Light Grey) of the stratigraphic succession, with the top squares (Magenta, Ma-Wh Corridor, and White Squares) containing about $75 \%$ of all known tetrapod tracks (Figure 2). The newly discovered dinosaur trackway LH-Y-1-001 is on the Yellow Square and it is the most basal trackway in the stratigraphic succession (Figure 2).

Fishes were the main vertebrate trace producers. Undichna appeared as a rather common ichnotaxon in all layers, as reported by Gibert et al. (1999). Tetrapods, represented by crocodilian and dinosaur traces, were identified by isolated manus and pes prints. The mean length of dinosaur footprint (tip of III digit to heel) was $337 \mathrm{~mm}$ (range 80$600 \mathrm{~mm}$ ). Tetrapod prints are frequently linked to tail drag marks, or the prints occur with Undichna and invertebrate traces; they may also occur as a profuse number $(n=80-90)$ of small, sub-rounded undetermined prints of with a mean diameter of 40 $\mathrm{mm}$ (Figure 3.6).

In general, tetrapod autopodia appeared preserved as blurred prints, with the digits not sharply defined, diffuse pes/manus outlines, and prints commonly stretched. Both prints and undertracks appear rather shallow, and overtracks, when present, irregular; sediment that fills the tracks is laminated in some parts, but not in others. Thus, the makers of most of the tetrapod traces could only be unequivocally determined in exceptional cases (Gibert at al., 2016). Despite this unexceptional preservation, two types of footprints may be sorted in the locality: (1) shallow prints that reflect the gross outline of the feet (Figure 3.2 and 3.5); and (2) deep, traceable prints that show a more detailed impression of the toes (Figure 3.1, 3.3, and 3.4).

1. The shallow prints tend to preserve an incomplete contour (Figure 3.2), whereas 


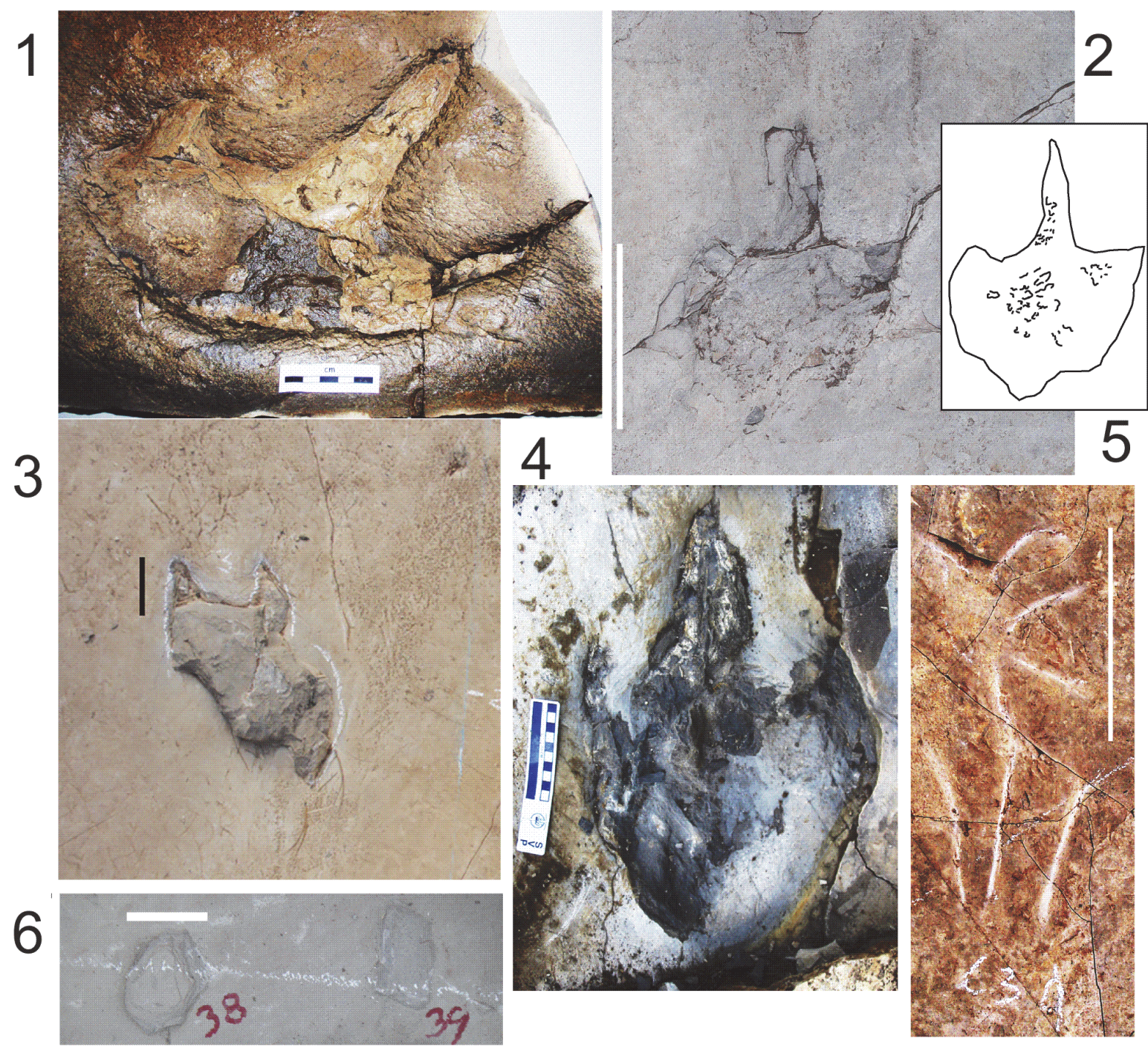

FIGURE 3. Preservation of tetrapod traces at Las Hoyas (Late Barremian, La Huérguina Formation). 1. Stretched isolated footprint (MCCM-LH- 6500) that was formerly attributed to Pteraichnus. 2. Dinosaur footprint of a trackway composed of two prints in White Square layer \#8.2, showing a chipped surface inside; scale bar $15 \mathrm{~cm}$. 3. Theropod left footprint of the trackway recorded in Magenta Square. 4. Theropod right footprint of the same trackway as Figure 3.3 recorded in Magenta Square. 5. Hand and foot of a crocodylomorph recorded in White Square, layer \#5, scale bar 13 $\mathrm{cm}$. The image has been equalized to enhance the scratches of the foot toes. 6 . Traces attributed to undetermined tetrapod preserved as sub-elliptical prints closely placed from MaWh Corridor (LH-29959).

some of the prints are scratches in the sediment (see the hand-foot of a crocodylomorph in Figure 3.5). None of this shallow-print type shows a well-shaped overtrack with inner layers; conversely the track is rather smooth or preserves internally a chipped surface (Figure 3.2).

2. The group of deep prints preserves the foot contour, even though foot contours can be unequally conserved throughout the same trackway. Unequally preserved footprints in the same trackway may combine sheared and well-shaped traces (Figure 3.3-4). The deep footprints display a stack of internal laminated overtracks, the outline is bounded by a displacement rim bulging around the track, and the rim is set of sharply visible radial fractures. A paradigmatic deep-type at Las Hoyas is the footprint once attributed to Pteraichnus (Figure 3.1, 4). 


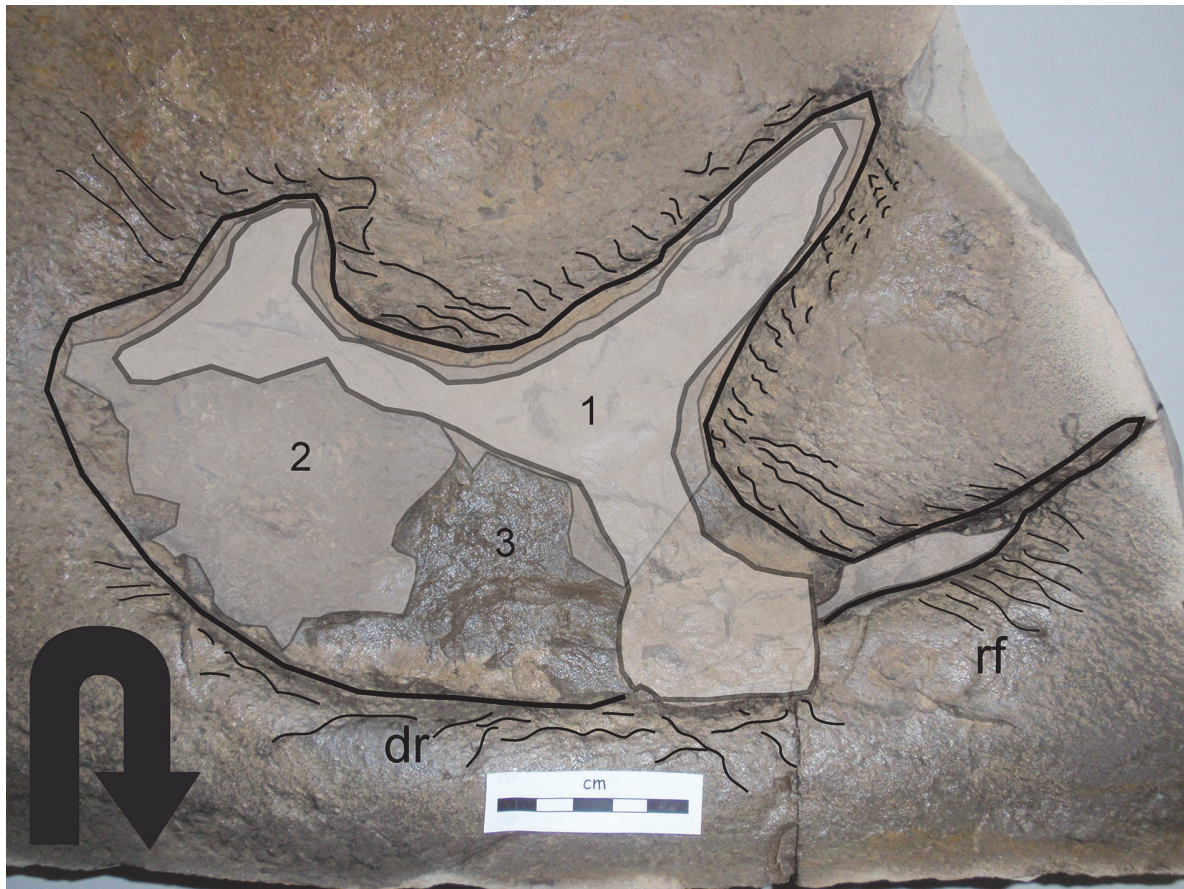

FIGURE 4. Drawing of the distorted footprint MCCM-LH 6500 (Las Hoyas, Late Barremian) showing the taphonomic features of a print likely produced on a moist to unsaturated microbial mat. 1-3: layers of sediment fill that form a stack of internal overtracks; dr: displacement rim; rf: radial fissures or striation marks.
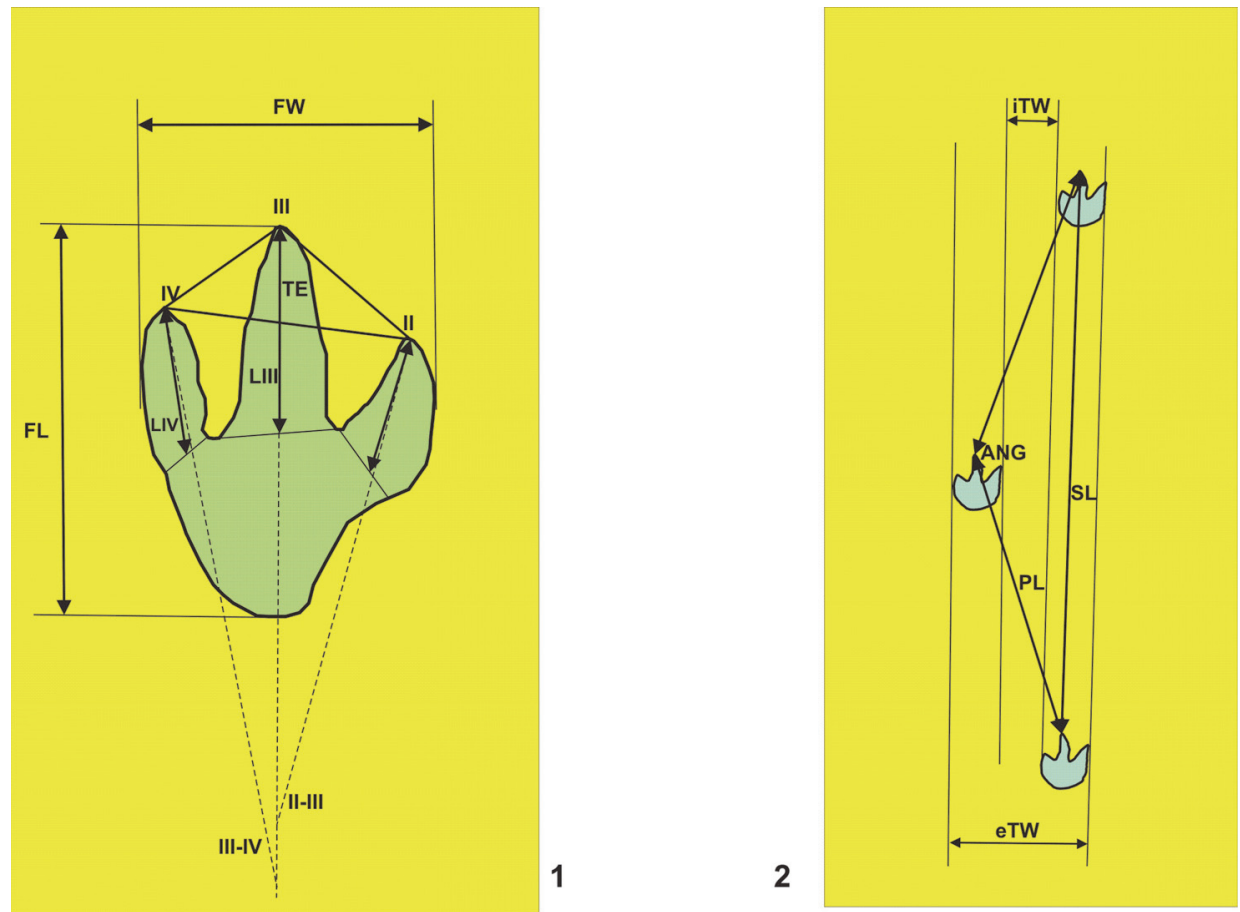

FIGURE 5. Measurements used in this study. 1. Variables related to a footprint: FL, footprint length; FW, footprint width; LII, LIII, LIV, length of the digits; II-III, angle between the axis of digit II and digit III; III-IV, the same angle relative to digits III and IV; TE, toe extension, that is, the anterior projection of digit III. 2. Variables related to a trackway: ANG, angle between three consecutive footprints; eTW, external trackway width; iTW, internal trackway width; PL, pace length; SL, stride length. 


\section{SYSTEMATIC ICHNOLOGY}

Methods. The new trackway-LH-Y-1-001-was mapped, measured, and quantified using the variables described in Figure 5. The trackway was also mapped using a Breuckmann SmartScan 3D HEcolor scanner, with 3D high resolution white light. Furthermore, a camera reflex Canon 5D mark II was used for photograph support. The hip height $(\mathrm{H})$ of the trackmaker was estimated using the method of Thulborn (1990) for theropod tracks longer than $25 \mathrm{~cm}(\mathrm{H}=4.9 \mathrm{FL})$ ( $\mathrm{FL}$ : footprint length). This method avoids the generalization of Alexander (1976) $(\mathrm{H}=4 \mathrm{FL})$, and it is more conservative with respect to the estimated speed.

Referred Material. LH-Y-1-001 was composed of four consecutive tridactyl footprints named LH-Y-1001/1, LH-Y-1-001/2, LH-Y-1-001/3 and LH-Y-1$001 / 4$, following the direction of movement (Figures 6-7).

Horizon. The trackway LH-Y-1-001 was found on the top layer of the Yellow Square (Figure 2). The Yellow Square is at the base of the stratigraphic succession of the excavated area defined between the West and East main faults (Figure 2).

Preservation. The footprints of LH-Y-1-001 are shallow, with incomplete contours; footprints are rather flat and covered by a thin, non-laminated overtrack (Figure 6).

\section{DESCRIPTION}

Trackway LH-Y-1-001 is composed of four tridactyl footprints (right-left-right-left) of medium size (Table 1) made by an animal walking in bipedal fashion (Figures 5-6). It shows a direction of movement of $234^{\circ}$ (Table 2). Both strides seem to be quite long $(292 \mathrm{~cm}$ and $317 \mathrm{~cm})$. In contrast, the pace angle is quite small $\left(154^{\circ}\right.$ as mean value). The first pace $(138 \mathrm{~cm})$ is shorter than the second $(165 \mathrm{~cm})$.

Print 1 (LH-Y-1-001/1) is incompletely preserved; only the central and lateral digits are visible. The medial digit, the heel surface, and the medial rear outline have not been preserved. In fact, the rear part of the print suggests that the proximal end of the autopodium did not, at least in this print, make contact with the substrate. At 13 $\mathrm{cm}$ in length, this incomplete print is only half the length of the remaining prints in the trackway. It is, however, slightly deeper than the rest (Figure 6.2).

Print 2 (LH-Y-1-001/2), with short digits, is unambiguously tridactyl and longer $(28 \mathrm{~cm})$ than wide $(24 \mathrm{~cm})$. The digits are slightly acuminate and the hypexes rather distally located. The heel sur- face is wide with a relatively broad posterior outline. This print is very shallow ( $<1 \mathrm{~cm}$ in depth) (Figure 6.3).

Print 3 (LH-Y-1-001/3) is also clearly tridactyl, with long, slender digits. Digit III is V-shaped, distally acuminate, and clearly longer than digits II and IV. Digit II is somewhat shorter than digit IV and shows slight medially curving. This track is also very shallow (Figure 6.4).

Print 4 (LH-Y-1-001/4) is poorly preserved making observation of the track morphology difficult. In fact, such measurements as total length and the width have not been considered for calculation of the means (Tables 1-2). Despite these issues, the general size and shape seem to be analogous to the preceding footprints $\left(n^{\circ} 2\right.$ and $n^{\circ}$ 3 ), and, in particular, this fourth footprint confirms the trackway pattern.

The mean footprint length/width ratio (FL/FW) (based on tracks 2 and 3 ) is 1.14 , confirming the tracks to be slightly longer than they are wide. At a mean of $10.1 \mathrm{~cm}$, digit III is clearly the longest of all; the TE projection (sensu Weems, 1992) is about $8.12 \mathrm{~cm}$ (Figure 5). Digits II and IV are clearly shorter than the middle digit (digit III), and the mean length of digit II is about $17.7 \%$ less than that of the digit IV (Table 1). The divarication angle (II-IV) is variable; print 2 shows a value of $20^{\circ}$ while that of print 3 is $39^{\circ}$. However, the latter print is the best preserved, thus $39^{\circ}$ might be the most accurate measure. The hip height $(\mathrm{H})$, calculated according to Thulborn (1990) for theropod footprints longer than $25 \mathrm{~cm}$, was $134.75 \mathrm{~cm}$, suggesting an animal some 4.0-4.5 m long, or a mediumsized theropod.

\section{DISCUSSION}

\section{Trackmaker Identification}

The features of the prints of trackway LH-Y-1001 (i.e., their generally elongated nature, acuminate digits, mesaxonic condition, the $\mathrm{V}$-shape of digit III, the rather medially directed digit II, the relatively straight digit IV, the fact that digit II is slightly shorter than digit IV, and the digit II-III divarication angle smaller than that of III-IV [Figure 5]), strongly indicate that the trackmaker was a theropod dinosaur. The size of the footprints suggests the dinosaur was medium-sized; the estimated hip height was about $134 \mathrm{~cm}$ and the estimated body length 4.0-4.5 $\mathrm{m}$. Identifying the trackmaker beyond that of it being a theropod is, however, not an easy matter. For example, bony foot elements for theropods are not abundant (especially in the European fossil 


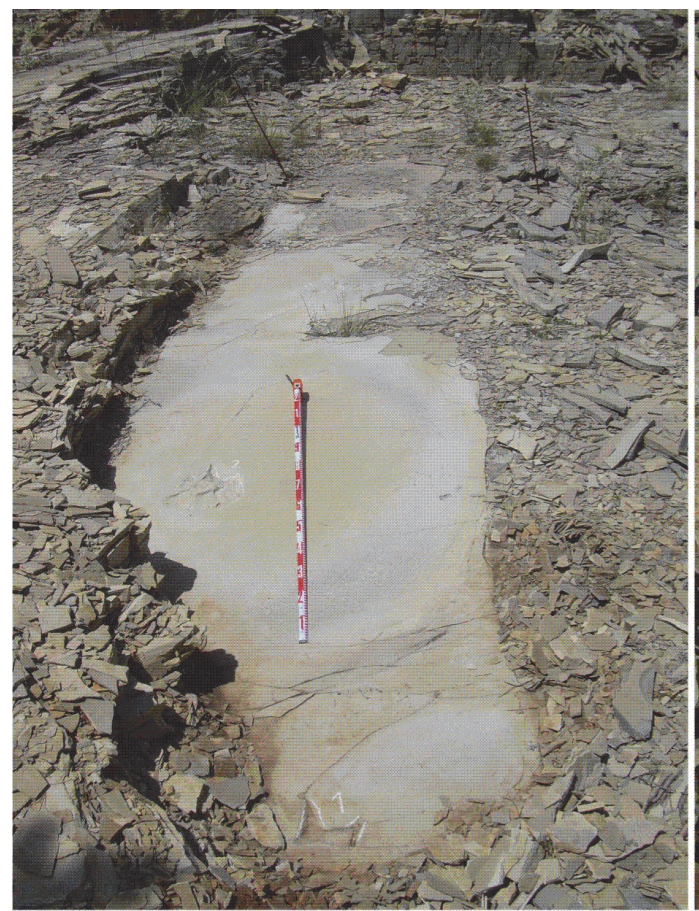

1

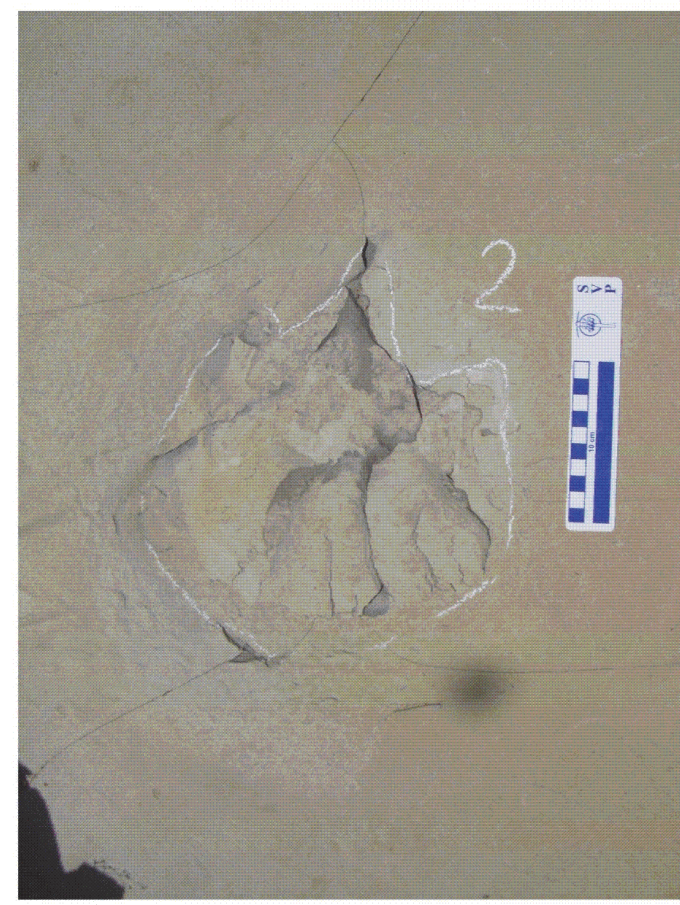

3

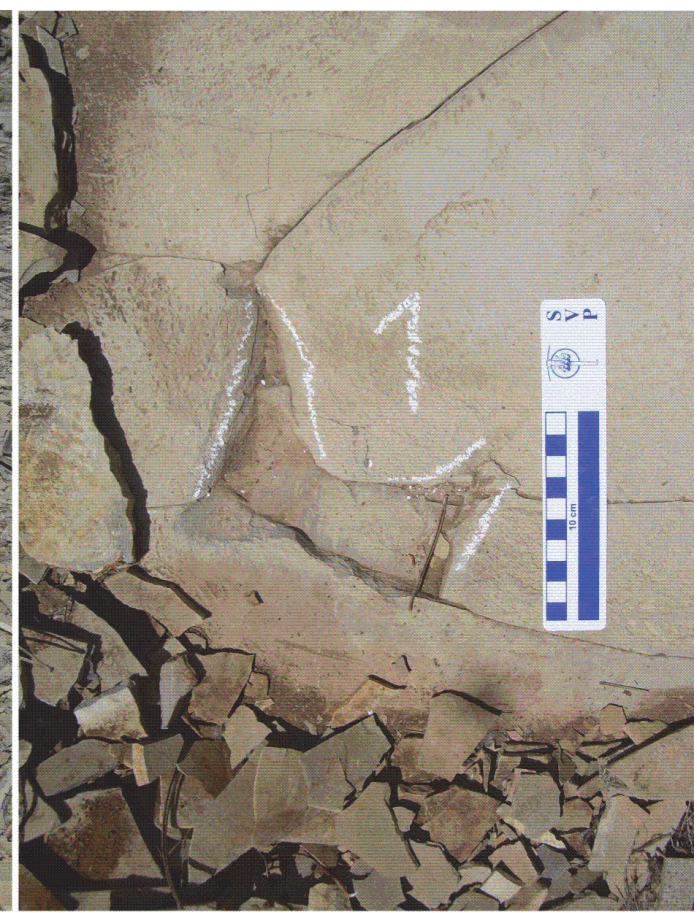

2

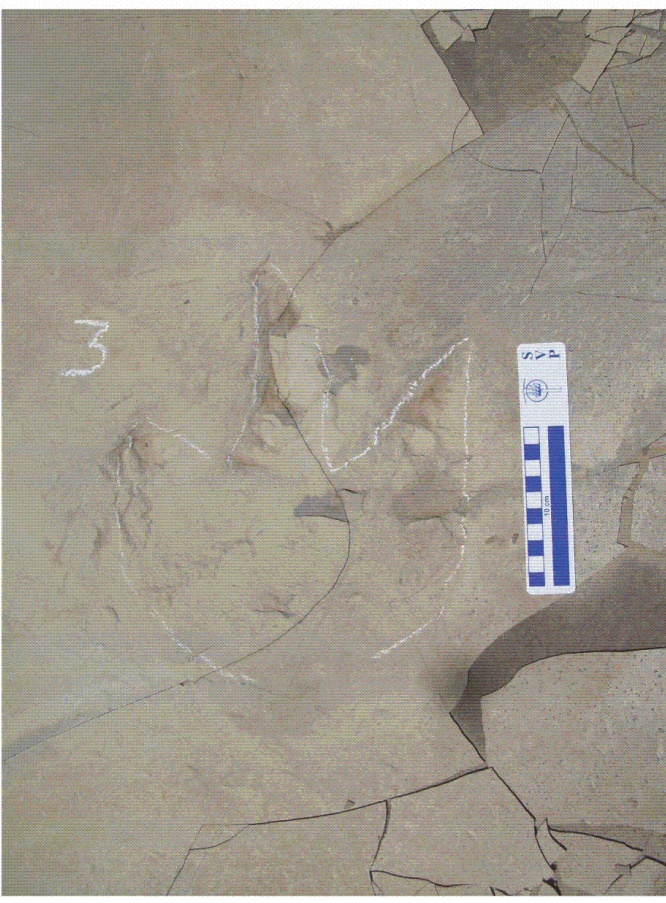

4

FIGURE 6. 1. Photograph of the trackway LH-Y-1-001 of the Late Barremian of Las Hoyas outcrop (La Huérguina Formation). 2. Footprint LH-Y-1-001/1. 3. Footprint LH-Y-1-001/2. 4. Footprint LH-Y-1-001/3. 


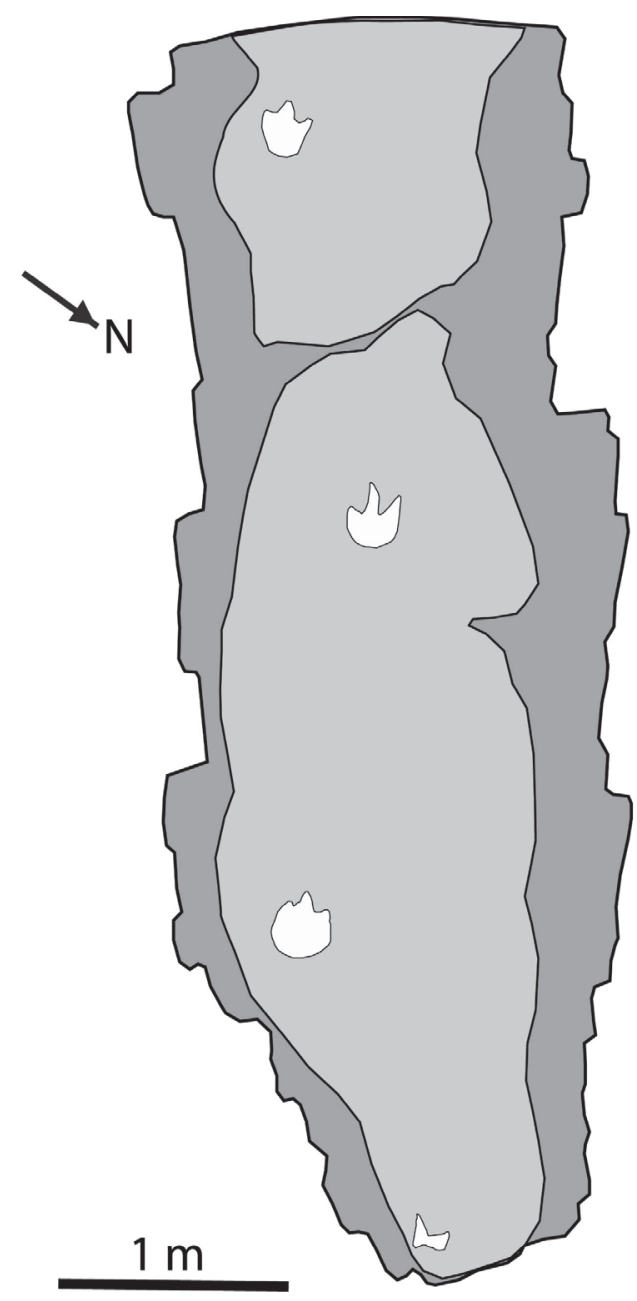

FIGURE 7. Map of the trackway LH-Y-1-001 from the Las Hoyas fossil site Late Barremian (La Huérguina Formation).

record), making it difficult to identify an animal with a foot that precisely matches the anatomy revealed by the present tracks (see Demathieu, 1981; Henderson, 2003; Wilson, 2005).

Interestingly, however, these tracks are about the same size as the feet of the well- preserved carcharodontosaurid dinosaur, Concavenator corcovatus (Ortega et al., 2010, Cuesta and Fregenal-Martínez, 2012), found in the same locality. A detailed study of the feet of Concavenator revealed the presence of foot pads, the general morphology of their soft parts (Cuesta et al., 2015), and showed the foot phalanges of digit III to be approximately $25.8 \mathrm{~cm}$ long, very similar to the $27.5 \mathrm{~cm}$ recorded for prints 2 and 3 of LH-Y-1-001. Indeed, when the distal part of the metatarsal is taken into account, the overall length of the feet match even better. Consequently, the length of the foot of Concavenator and the present footprints appear to be equivalent. In addition, the calculated value for the hip height of the trackmaker using Thulborn's equation results in a hindlimb length of $134.75 \mathrm{~cm}$ while the Concavenator skeleton has a hindlimb length of $137.9 \mathrm{~cm}$. The agreement between these values cannot, however, unequivocally identify the trackmaker even as a carcharodontosaurid. In fact, the foot bones of the members of Carcharodontosauridae are poorly represented in the fossil record. Despite that, some carcharodontosaurid foot fossils are available for comparison. However, while specimen NCSM 14345 of the North American Acrocanthosaurus atokensis (Stovall and Langston, 1950; Currie and Carpenter, 2000) presents an almost complete foot, it lacks the more distal phalanges. Further, Tyrannotitan chubutensis (Novas et al., 2005) and Mapusaurus roseae (Coria and Currie, 2006) are only represented by few or incomplete metatarsals and few phalanges, and the bones of the latter may, in fact, belong to different individuals (Coria and Currie, 2006).

\section{Trackmaker Movement}

One of the most significant contributions of paleoichnology to dinosaurology is the possibility of estimating progression speeds, and even more important, indirect estimations of the momentum of the trackmaker. The first estimate of a trackmaker's speed, inferred from its own trackway, was made by Alexander (1976), who reported the following relationship:

$$
\mathrm{V}=0.25 \times \mathrm{g}^{0.5} \times \mathrm{SL}^{1.67} \times \mathrm{H}^{-1.17}
$$

where $V$ is the trackmaker's speed, $g$ the acceleration of gravity, $\mathrm{SL}$ the stride length, and $\mathrm{H}$ the hip height.

The use of this equation with the trackway LHY-1-001 suggests the animal, although probably accelerating, had developed a mean velocity of 3.3 $\mathrm{m} / \mathrm{s}(12.7 \mathrm{~km} / \mathrm{h})$. Interestingly, the biodynamic index $(\mathrm{SL} / \mathrm{H})$ of 2.26 for the studied trackway is within the range of trotting but not running (sensu Thulborn, 1982). Thus, the putative trackmaker, a theropod dinosaur, may have been exhibiting a trotting behavior. By way of comparison, human professional marathon runners have a mean race speed (over the $42 \mathrm{~km}$ course) of about $5.5 \mathrm{~m} / \mathrm{s}$ (20 $\mathrm{km} / \mathrm{h}$ ). Thus, while the trackmaker may have been trotting, its mean velocity was lower than that of a human running a marathon. These findings should, of course, be taken cautiously since only two full strides are available for measurement. Further, the 
TABLE 1. Track measurements for the trackway LH-Y-1-001 from the Las Hoyas fossil locality. Rot, angle between the track and the trackway midlile (negative value implies inward rotation). H, hip height sensu Thulborn (1990). The rest of variables as in the Figure 5.1.

\begin{tabular}{|c|c|c|c|c|c|c|c|c|c|c|c|c|}
\hline Track & $\mathbf{F L}$ & FW & LII & LIII & LIV & TE & II-III & III-IV & IIIIV & FL-FW/FW & Rot & $\mathrm{H}$ \\
\hline 1 & 13 & 15 & & 11 & 5 & & & $41^{\circ}$ & & (-) 0.13 & $-11^{\circ}$ & \\
\hline 2 & 28 & 24 & 4.5 & 7.5 & 2.5 & 6.25 & $11^{\circ}$ & $9^{\circ}$ & $20^{\circ}$ & 0.16 & $0^{\circ}$ & 137.2 \\
\hline 3 & 27 & 24 & 6.2 & 12.7 & 10.5 & 10 & $18^{\circ}$ & $24^{\circ}$ & $39^{\circ}$ & 0.12 & $-4^{\circ}$ & 132.3 \\
\hline 4 & 26 & 22 & 8 & 12.5 & 8 & 5.5 & $24^{\circ}$ & $26^{\circ}$ & $46^{\circ}$ & 0.18 & $-12^{\circ}$ & 127.4 \\
\hline Mean & 27.5 & 24 & 5.35 & 10.1 & 6.5 & 8.12 & $14.5^{\circ}$ & $16.5^{\circ}$ & $29.5^{\circ}$ & 0.14 & $-6.7^{\circ}$ & 134.75 \\
\hline
\end{tabular}

TABLE 2. Trackway measurements from the trackway LH-Y-1-001 from the Las Hoyas fossil locality. H, hip height sensu Thulborn (1990); V, speed of progression ( $\mathrm{km} / \mathrm{h})$; DIR, trackway direction. The rest of the measurements as in Figure 5.2 and Table 1.

\begin{tabular}{|c|c|c|c|c|c|c|c|c|c|c|}
\hline Tracks & SL & PL & ANG & SL/H & SL/FL & eTW & iTW & iTW/FW & $\mathbf{v}$ & DIR \\
\hline $1-3$ & 292 & & $151^{\circ}$ & & 10.61 & & & & & \\
\hline $2-4$ & 317 & & $157^{\circ}$ & & 11.52 & & & & & \\
\hline $1-2$ & & 138 & & & & & & & & \\
\hline $2-3$ & & 165 & & & & & & & & \\
\hline $3-4$ & & 156 & & & & & & & & \\
\hline Mean & 304.5 & 153 & $154^{\circ}$ & 2.26 & 11.06 & 53.7 & 16.2 & 0.67 & 12.7 & $234^{\circ}$ \\
\hline
\end{tabular}

second pace in the trackway is $19.5 \%$ longer than the first (165 vs. $138 \mathrm{~cm})$. Despite the fact that the third pace is shorter $(156 \mathrm{~cm})$, the two preserved strides (292 and $317 \mathrm{~cm}$, respectively) could suggest that the trackmaker may have been accelerating. However, similar physical evidence of acceleration in the fossil record is very scant (Kim and Huh, 2010).

Dinosaur skeletal organization is variable among clades, but their biomechanics suggest that many of them could run. Indeed, some appear to have been fast runners, especially small-tomedium size theropods and certain bipedal ornithopods (Russell and Béland, 1976; Thulborn and Wade, 1979, 1984; Farlow et al., 2000; Persons IV and Currie, 2016). However, trackways produced by running dinosaurs are quite rare, and most estimates from bipedal trackways suggest speeds of <10 km/h (Thulborn, 1990; Pérez-Lorente, 1996; Farlow et al., 2000). Some cases of "quick" dinosaur trackways have, however, been reported (Russell and Béland, 1976; Thulborn and Wade, 1979; Thulborn, 1981; Thulborn and Wade, 1984), with some suggesting speeds of up to $40 \mathrm{~km} / \mathrm{h}$ (Farlow, 1981; Viera and Torres, 1995; Irby, 1996.). The theropod trackway reported here would, therefore, be on the average of that "quick" dinosaur pattern.

\section{Palaeoenvironmental Implications of Trackway LH-Y-1-001}

The palaeoenviromental implications of LH-Y1-001 trackway allow us to interpret the different types of track preservation and to review the pattern of relative abundance of tetrapod traces at Las Hoyas. The fact that most of the fossil record of Las Hoyas was influenced by the contemporaneous production of microbial mats (Gupta et al., 2008; Iniesto et al., 2016; Iniesto et al., 2017) suggests that these might have also affected the preservation of the tetrapod tracks. The production of carbonate by growing microbial communities characterizes the facies in which the dinosaur and crocodile tracks are found (Buscalioni and FregenalMartínez, 2010). These facies were deposited during periods in which the water column was reduced to probably several centimeters in depth (Fregenal-Martínez, 1998), i.e., the drier periods that affected this seasonal, subtropical wetland ecosystem.

Microbial mats favor the preservation of tetrapod tracks because a microbially-stabilized substrate behaves more plastically, the microbiallybound sediment preserves the imprint, and microbial mats often induce early cementation (Marty et al., 2009; Carmona et al., 2011; Dai et al., 2015). Further, a high spectrum of variation in footprint 
shape has been experimentally demonstrated in present-day tidal flat environments with growing microbial mats and human trackmakers (Marty et al., 2009). These authors found that due to differences in water content and thickness of microbial mats related to the underlying sediment, the same trackmaker may produce a wide range of preservation types. Therefore, the two different morphologies (i.e., shallow or deep prints, see Figure 3) found at Las Hoyas were likely influenced by microbial mats.

The shallow footprints at Las Hoyas show analogies with those described by Marty et al. (2009) in dry to damp mats. In accordance with their results, the theropod footprint with a chipped surface inside (Figure 3.2) would suggest that the dinosaur cracked the mat after pressing its foot into the sediment. The absence of a well-shaped overtrack, in this case, indicates a simple filling up. On the other hand, the deep footprints preserve better details of the toe outlines (Figure 3.1, 3.3 and 3.4). In these deep prints found at Las Hoyas (Figure 3.1 and 3.4), the underlying sediment was not penetrated. Instead, the superficial layer with the microbial mat was compressed and pushed into the underlying sediment (Figure 4). The impact of the foot formed a displacement rim all around the track, whereas the superficial microbial mat led to cracking around the foot (Figure 4) forming striation marks (Dai et al., 2015). These features are analogous to those of human prints produced in water unsaturated mats (see figure 5E in Marty et al., 2009); these taphonomic details have also been recognized in ornithopod tracks of the Early Cretaceous Jiaguan Formation (Dai et al., 2015). Furthermore, the distortion of some dinosaur footprints at Las Hoyas (Figure 3.1 and 3.3) prompts us to think that they could have been produced in a more watery setting of a slippery surface able to shear the tracks.

The preservation of the trackway LH-Y-1-001 matches with those produced on dry to damp mats following Marty et al. (2009). The presence of an irregular internal overtrack (Figure 6.3 and 6.4) might indicate that the mat kept growing covering the shallow true track. Moreover, running and jumping dinosaurs tend to produce ill-defined prints (Marty et al., 2009), and the optimal substrate consistency (soft and watered mud) for print formation may be mechanically unsuitable for running in heavy animals. Hence, the type of preservation of LH-Y-1-001 concurs with a dry substrate required for a running locomotion pattern.

\section{CONCLUSIONS}

The footprints of trackway LH-Y-1-001 are noteworthy since they may record a fast moving dinosaur. The preservation of the footprints was influenced by microbial mats and the features observed in the three complete footprints are in agreement with their production on a dry to damp mat substrate. The poor preservation of the prints is probably also a consequence of the trotting of the trackmaker. The identity of the trackmaker cannot be known for certain, however, the trackway dimensions suggest that the trackmaker was an agile, medium-sized theropod with a long stride, features shared by Concavenator corcovatus known from this locality.

Reassessment on the number of tetrapod tracks at Las Hoyas suggests that they became more abundant towards the top of the stratigraphic succession (i.e., Magenta to White Square). In particular, the abundance of crocodile and dinosaur trackways in the White Square (Figure 2) indicates the recurrent presence of medium-to-large sized individuals. Still, we need to prove whether the increase in the number of archosaur tracks implies a change in the conditions of the palaeoecosystem. The big dinosaurs may have been more abundant only at that moment, and they were walking or crossing a shallow ponding zone as incidental organisms, insomuch as only their locomotion traces have been recorded.

\section{ACKNOWLEDGMENTS}

This paper was produced as part of project CGL2013-42643P for the study of the Las Hoyas site and SIFA161418 for the scanning of the trackway. Fundings are from the Spanish Ministerio de Economía y Competitividad (MINECO) and Viceconsejería de Educación Cultura y Deportes of Junta de Castilla-La Mancha. Article revised by A. Burton native corrector of English for scientific articles. PaleoyMas Company carried out the project of scanning and scaled photogrammetry. Thanks also to two anonymous referees for proposing very interesting suggestions improving remarkably the quality of the manuscript. 


\section{REFERENCES}

Alexander, R. McN., 1976. Estimates of speeds of dinosaurs. Nature, 261:129-130.

Bailleul, A., Ségalen, L., Buscalioni, A.D., Cambra-Moo, O., and Cubo, J. 2011. Palaeohistology and preservation of tetrapods from Las Hoyas (Lower Cretaceous, Spain). Comptes Rendus Palevol, 10:367-80.

Briggs, D.E.G., Wilby, P.R.W., Pérez-Moreno, B.P., Sanz, J.L., and Fregenal-Martínez, M. 1997. The mineralization of dinosaur soft tissue in the Lower Cretaceous of Las Hoyas, Spain. Journal of the Geological Society, 154:587-588.

Buatois, L.A. and Mángano, M.G. 2011. Ichnology: Organism-substrate interactions in space and time. Cambridge University Press. Cambridge (United Kingdom), 366 pp.

Buatois, L.A., Mángano, M.G., Fregenal-Martínez, M.A., and de Gibert, J.M. 2000. Short-term colonization trace-fossil assemblages in a carbonate lacustrine konservat-lagerstätte (Las Hoyas fossil site, Lower Cretaceous, Cuenca, central Spain). Facies, 43:145-156.

Buscalioni, A.D. and Fregenal-Martínez, M.A. 2010. A holistic approach to the palaeoecology of Las Hoyas Konservat-Lagerstätte (La Huérguina Formation, Lower Cretaceous, Iberian Ranges, Spain). Journal of Iberian Geology, 36(2):297-326.

Buscalioni, A.D., Fregenal-Martínez, M.A., Bravo, A., Poyato-Ariza, F.J., Sanchíz, B., Báez, A.M., Cambra-Moo, O., Martín-Closas, C., Evans, S.E., and Marugán-Lobón, J. 2008. The vertebrate assemblage of Buenache de la Sierra (Upper Barremian of Serrania de Cuenca, Spain). Cretaceous Research, 29:687-710.

Buscalioni, A. D. and Poyato-Ariza, F.J. 2016. From taphonomy to palaeoecology, p. 232-237. In Poyato-Ariza, F.J. and Buscalioni, A.D. (eds.), Las Hoyas: A Cretaceous Wetland. Verlag Dr. Friedrich Pfeil, München.

Carmona, N., Bournod, C., Pónce, J.J., and Cuadrado, D. 2011. The role of microbial mats in the preservation of bird footprints: a case study from the mesotidal Bahía Blanca estuary (Argentina). In Microbial mats in siliciclastic depositional systems through time. SEPM Special Publication, 101:37-45.

Coria, R.A. and Currie, P.J. 2006. A new carcharodontosaurid (Dinosauria, Theropoda) from the Upper Cretaceous of Argentina. Geodiversitas, 28:71-118.

Cuesta, E., Díaz-Martínez, I., Ortega, F., and Sanz, J.L. 2015. Did all theropods have chickenlike feet? First evidence of a non-avian dinosaur podotheca. Cretaceous Research, 56:5359.

Cuesta, E. and Fregenal-Martínez, M.A. 2012. Taphonomic study of Concavenator corcovatus (Theropoda: Carcharodontosauria) from Las Hoyas fossil site (Lower Cretaceous, Serranía de Cuenca, Spain). Fundamental, 20:57-58.

Currie, P.J. and Carpenter, K. 2000. A new specimen of Acrocanthosaurus atokensis (Theropoda, Dinosauria) from the Lower Cretaceous Antlers Formation (Lower Cretaceous, Aptian) of Oklahoma, USA. Geodiversitas, 22:207-246.

Dai, H., Xing, L., Marty, D., Zhang, J., Persons, W.S., Hu, H., and Wang, F. 2015. Microbiallyinduced sedimentary wrinkle structures and possible impact of microbial mats for the enhanced preservation of dinosaur tracks from the Lower Cretaceous Jiaguan Formation near Qijian (Chongqing, China). Cretaceous Research, 53:98-109.

Demathieu, G.R. 1981. Comparaison des informations fournies par l'ichnologie des Vertébrés et a par la paleontology ostéologique dans le domaine de la chronologie. Bulletin Scientifique de Bourgogne, 34:5-12.

Diéguez, C., Martín-Closas, C., Meléndez, N., Rodriguez-Lárazo, J., and Trinçao, P. 1995. Biostratigraphy. p. 77-79, In Meléndez, N. (ed). Las Hoyas. A Konservat-Lagerstätte, Cuenca, Spain. Madrid, Ediciones Universidad Complutense de Madrid.

Farlow, J.O. 1981. Estimates of dinosaur speeds from a new trackway site in Texas. Nature, 294:747-748.

Farlow, J.O., Gatesy, S.M., Holtz, T.R., Hutchison, J.R., and Robinson, J.M. 2000. Theropod Locomotion. American Zoologist, 40:640-663.

Fregenal-Martínez, M.A. 1998. Análisis de la cubeta sedimentaria de Las Hoyas y su entorno paleogeográfico (Cretácico Inferior, Serranía de Cuenca). Sedimentología y aspectos tafonómicos del yacimiento de Las Hoyas. Unpublished Ph.D. Thesis, Universidad Complutense de Madrid, Marid, Spain. 
Fregenal-Martínez, M.A., Buatois, L.A., and Mángano, M.G. 1995. Invertebrate trace fossils from Las Hoyas fossil site (Serranía de Cuenca, Spain) - Paleonvironmental interpretations. 2nd International Symposium on Lithographic Limestones, Cuenca, Extended Abstracts, 65-70.

Fregenal-Martínez, M.A. and Buscalioni, A.D. 2009. Las Hoyas Konservat-Lagerstätte: a fieldtrip to a Barremian subtropical continental (wetland) ecosystem. In Alcalá, L. and RoyoTorres, R. (coords). Mesozoic terrestrial ecosystems in Eastern Spain, Teruel, Fundación Conjunto Paleontológico de Teruel-Dinópolis, Fundamental, 14:131-152.

Fregenal-Martínez, M.A. and Meléndez, N. 2000. The lacustrine fossiliferous deposits of the Las Hoyas subbasin (Lower Cretaceous, Serranía de Cuenca, Iberian ranges, Spain), p. 303313. In Gierlowski-Kordesh, E.H. and Kelts, K.R. (eds,), Lake Basins through Space and Time. AAPG Studies in Geology 46.

Fregenal-Martínez, M.A. and Meléndez, N. 2016. Environmental reconstruction: a historical review, p.14-28. In Poyato-Ariza, F.J. and Buscalioni, A.D. (eds.). Las Hoyas: A Cretaceous Wetland. Verlag Dr. Friedrich Pfeil, München.

Fregenal-Martínez, M.A. and Moratalla, J.J. 1995. Paleoichnology, p. 71-75. In Meléndez, N. (ed.). Las Hoyas. A Konservat-Lagerstätte, Cuenca, Spain. Madrid, Ediciones Universidad Complutense de Madrid.

Fregenal-Martínez, M.A., Meléndez, N., 2016. Environmental reconstruction: a historial review, in: Ed. by Poyato-Ariza, J.F., Buscalioni, A.D. (Eds.), Las Hoyas: a Cretaceous wetland. Verlag Dr. Friedrich Pfeil, München, Germany, pp 14-28.

Fregenal-Martínez, M.A., Muñoz-Garcia, M.B., Buscalioni, A.D., Elez, J., and de la Horra, R. 2014. The karstic habitat of spelaeogriphaceans from Las Hoyas fossil site (Upper Barremian, Serrania de Cuenca, Spain), in: Rocha, R., Pais, J., Kullberg, J.C., Finney, S. (Eds). STRATI 2013. At the cutting edge of Stratigraphy. Springer, Berlin, pp. 655-658.

Gibert, J.M., Buatois, L.A., Fregenal-Martínez, M.A., Mángano, G., Ortega, F., Poyato-Ariza, F.J., and Wenz, S. 1999. The fish trace fossil Undichna from the Cretaceous of Spain. Palaeontology, 42:409-427.

Gibert, J.M., Moratalla, J.J., Mángano, M.G., and Buatois, L.A. 2016. Palaeoichnology, p. 195201. In Poyato-Ariza, F.J. and Buscalioni, A.D. (eds.). Las Hoyas: A Cretaceous wetland. Verlag Dr. Friedrich Pfeil, München.

Gupta, N.S., Cambra-Moo, O., Briggs, D.E.G., Love, G.D., Fregenal-Martínez, M.A., and Summons, R.E. 2008. Molecular taphonomy of macrofossils from the Cretaceous Las Hoyas Formation, Spain. Cretaceous Research, 29:1-8.

Henderson, D.M. 2003. Footprints, trackways, and hip heights of bipedal dinosaurs - testing hip height predictions with computer models. Ichnos, 10:99-114.

Iniesto, M., Buscalioni, A.D., Guerrero, M.C., Benzerara, K., Moreira, D., and López-Archilla, A.I. 2016. Involvement of microbial mats in early fossilization by decay delay and formation of impressions and replicas of vertebrates and invertebrates. Scientific Reports, 6:25716; doi: $10.1038 /$.

Iniesto, M., Villalba, I., Buscalioni, A.D., Guerrero, M.C. and López-Archilla, A.I. 2017. The Effect of microbial Mats in the Decay of Anurans with Implications for Understanding Taphonomic Processes in the Fossil Record. Scientific Reports, 7:45160; doi: 10.1038/.

Irby, G.V. 1996. Paleoichnological evidence for running dinosaur worldwide. Museum of North Arizona, Bulletin, 60:109-112.

Kim, B.S. and Huh, M. 2010. Analysis of the acceleration phase of a theropod dinosaur based on a Cretaceous trackway from Korea. Palaeogeography, Palaeoclimatology, Palaeoecology, 293:1-8.

Llandres, M.S., Vullo, R., Marugán-Lobón, J., Ortega, F., and Buscalioni, A.D. 2013. An articulated hindlimb of a basal iguanodont (Dinosauria, Ornithopoda) from the Early Cretaceous Las Hoyas Lagerstätte (Spain). Geological Magazine, 150(3):572-576.

Lockley, M., Logue, T.J., Moratalla, J.J., Hunt, A.P., Schultz, R.J., and Robinson, J.W. 1995. The fossil trackway Pteraichnus is pterosaurian, not crocodilian: implications for the global distribution of pterosaur tracks. Ichnos, 4:7-20.

Martín-Closas, C. and Diéguez, C. 1998. Charophytes from the Lower Cretaceous of the Iberian Ranges (Spain). Palaeontology, 41:1133-1152.

Marty, D., Strasser, A., and Meyer, Ch. A. 2009. Formation and taphonomy of human footprints in microbial mats of present-day tidal-flat environments: implications for the study of fossil footprints. Ichnos, 16(1-2):127-142. 
Moratalla, J.J., Lockley, M.G., Buscalioni, A.D., Fregenal-Martínez, M.A., Meléndez, N., Ortega, F., Pérez-Moreno, B.P., Pérez-Asensio, E., Sanz, J.L., and Schultz, R.J. 1995. A preliminary note on the first tetrapod trackways from the lithographic limestones of Las Hoyas (Lower Cretaceous, Cuenca, Spain). Geobios, 28:777-782.

Novas, F.E., de Valais, S., Vickers-Rich, P., and Rich, T. 2005. A large Cretaceous theropod from Patagonia, Argentina, and the evolution of carcharodontosaurids. Naturwissenschaften, 92:226-230.

Ortega, F., Escaso, F., and Sanz, J.L. 2010. A bizarre, humped Carcharodontosauria (Theropoda) from the Lower Cretaceous of Spain. Nature, 467:203-206.

Pérez-Lorente, F. 1996. Pistas terópodas en cifras. Zubía, 14:37-55.

Pérez-Moreno, B.P., Sanz, J.L., Buscalioni, A.D., Moratalla, J.J., Ortega, F., and RasskinGutman, D. 1994. A unique multitoothed ornithomimosaur from the Lower Cretaceous of Spain. Nature, 30:363-367.

Persons IV, W.S. and Currie, P.J. 2016. An approach to scoring cursorial limb proportions in carnivorous dinosaurs and an attempt to account for allometry. Scientific Reports, 6:1-12.

Poyato-Ariza, F.J., Talbot, M.R., Fregenal-Martínez M.A., Meléndez, N., and Wenz, S. 1998. First isotopic and multidisciplinary evidence for non marine coelacanths and pycnodontiform fishes: palaeoenvironmental implications. Palaeogeography, Palaeoclimatology, Palaeoecology, 144:65-84.

Russell, D.A. and Béland, P. 1976. Running Dinosaurs. Nature, 264:486.

Stovall, J.W. and Langston, W. Jr. 1950. Acrocanthosaurus atokensis, a new genus and species of Lower Cretaceous Theropoda from Oklahoma. The American Midland Naturalist, 43:696728.

Thulborn, R.A. 1981. Estimates speed of a giant theropod dinosaur. Nature, 292:273.

Thulborn, R.A. 1982. Speeds and gaits of dinosaurs. Paleogeography, Palaeoclimatology, Palaeoecology, 38:227-256.

Thulborn, R.A. 1990. Dinosaur Tracks. Chapman and Hall, London. 410 pp.

Thulborn, R.A. and Wade, M. 1979. Dinosaur stampede in the Cretaceous of Queensland. Lethaia, 12:275-279.

Thulborn, R.A. and Wade, M. 1984. Dinosaur trackways in the Winton Formation (MidCretaceous) of Queensland. Memoirs of the Queensland Museum, 21:413-517.

Viera, L.I. and Torres, J.A. 1995. Análisis comparativo sobre dos rastros de Dinosaurios Terópodos: Forma de marcha y velocidad. Munibe, 47:53-56.

Vullo, R., Buscalioni, A.D., Marugán-Lobón, J., and Moratalla, J.J. 2009. First pterosaur remains from the Early Cretaceous Lagerstätte of Las Hoyas, Spain: palaeoecological significance. Geological Magazine, 146:931-936.

Weems, R.E. 1992. A re-evaluation of the taxonomy of Newark Supergroup saurischian dinosaur tracks, using extensive statistical data from a recently exposed tracksite near Culpeper, Virginia. Virginia Division of Mineral Resources Publication, 119:113-127.

Wilson, J.A. 2005. Integrating ichnofossil and body fossil records to estimate locomotor posture and spatiotemporal distribution of early sauropod dinosaurs: a stratocladistic approach. Paleobiology, 31(3):400-423. 